\title{
MAPEAMENTO DA Araucaria angustifolia UTILIZANDO RECEPTORES GPS
}

\author{
Diego Luis Venancio ${ }^{1}$, Attilio Antonio Disperati ${ }^{2}$, Ricardo Vilar Neves ${ }^{3}$
}

(recebido: 13 de julho de 2009; aceito: 30 de junho de 2010)

RESUMO: Compararam-se, neste trabalho, os resultados do mapeamento planimétrico das árvores de Araucária (Araucaria angustifolia), utilizando a tecnologia GPS nos modos estático diferencial (posicionamento relativo) e estático absoluto. A área de estudo refere-se ao Campus Universitário de Irati - UNICENTRO, no estado do Paraná, Brasil. O mapeamento apontou a presença de 264 Araucárias, sendo possível o posicionamento relativo de 141 árvores, com a precisão variando de 6 a $84 \mathrm{~cm}$; o posicionamento absoluto, possível em todas as Araucárias, apresentou variação de 5 a $14 \mathrm{~m}$. O posicionamento relativo foi possível em $30 \%$ das Araucárias onde a declividade foi $>30 \%$ e em $57 \%$ dos casos em que a área basal foi $>16 \mathrm{~m}^{2} / \mathrm{ha}$. Pode-se concluir que o posicionamento relativo possui precisão suficiente para a localização das Araucárias, enquanto o posicionamento absoluto pode causar confusão devido ao baixo grau de precisão quanto ao posicionamento planimétrico. O resultado do posicionamento relativo foi influenciado pela declividade e área basal, principalmente em condições de elevada declividade e elevada área basal.

Palavras-chave: Floresta com araucária, pinheiro-do-Paraná, posicionamento geográfico, NAVSTAR-GPS.

\section{MAPPING OF Araucaria angustifolia TREES USING GPS RECEIVERS}

\begin{abstract}
This study makes use of GPS technology in differential mode (relative positioning) and absolute mode in a Mixed Ombrophilous Forest in order to map the Araucaria angustifolia trees that occur in the area of study (Campus of Irati - UNICENTRO) in Paraná State, Brazil. The fieldwork pointed out the presence of 264 Araucárias in the area of study, the relative positioning was possible in 141 cases with precision ranging from 6 to $84 \mathrm{~cm}$; absolute positioning was possible in all cases with precision ranging from 5 to $14 \mathrm{~m}$. The relative positioning was possible in 30\% of the Araucárias where slope was > 30\% and in 57\% of cases in which the basal area was $>16 \mathrm{~m} 2 / \mathrm{ha}$. It can be concluded that the relative positioning accuracy is sufficient for the location of the Araucárias, while the absolute position can cause confusion due to the low degree of planimetric accuracy position. The results of the relative positioning were influenced by slope and basal area, especially in conditions of high slope and high basal area.
\end{abstract}

Key words: Araucária forest, araucaria tree, geographic positioning, NAVSTAR-GPS.

\section{INTRODUÇÃO}

O GPS, acrônimo de Global Positioning System, tem-se tornado uma tecnologia extremamente útil e inovadora para uma série de atividades que necessitam de posicionamento e podem-se citar aquelas relacionadas à Cartografia, Meio Ambiente, Controle de Frota de Veículos, Navegação Aérea e Marítima, Geodinâmica, Agricultura, etc (MONICO, 2000, p. 15).

$\mathrm{Na}$ área florestal, a tecnologia GPS tem tido diversas aplicações, tais como: instrumento de atualização de bases cartográficas de empresas florestais e locação de experimentos ambientais (RODRIGUES-PEREZ et al., 2006), na localização e marcação de árvores em inventário florestal (FIGUEIREDO et al., 2008), no mapeamento simultâneo das árvores e das colheitadeiras (harvesters) florestais (OHMA et al., 2007), no mapeamento e danos causados por incêndios florestais (EL-SHEIMY \& WRIGHT, 2003) e no microplanejamento florestal (BERNARDI \& PONTES, 2006).

Naesset (2001) comentou que a precisão dos resultados nas determinações de posicionamento depende do procedimento utilizado e do aparelho receptor GPS usado e como resultado pode-se obter precisão de 10 metros (posicionamento absoluto) até milímetros (posicionamento usando sinais L1 e L2).

Atualmente, o aumento de precisão requerido no posicionamento dos pontos no terreno para atividades de manejo florestal, colheita florestal ou acompanhamento de pesquisas científicas, demanda a utilização de equipamento que forneça grande precisão. Os receptores GPS atuais

\footnotetext{
${ }^{1}$ Engenheiro Ambiental, Mestre em Ciências Florestais - Laboratório de Fisiologia do Exercício - Centro de Ciências da Saúde Universidade Estadual do Centro Oeste/UNICENTRO - PR-153, km 7 - Bairro Riozinho - 84500-000 - Irati, PR diegoluisvenancio@yahoo.com

${ }^{2}$ Engenheiro Florestal, Professor PhD. em Sensoriamento Remoto - Departamento de Engenharia Florestal - Universidade Estadual do Centro Oeste/UNICENTRO - PR-153, km 7 - Bairro Riozinho - 84500-000 - Irati, PR - disperati@avalon.sul.com.br

${ }^{3}$ Engenheiro Cartógrafo, Mestre em Ciências Geodésicas - Serviço Florestal Brasileiro - Ministério do Meio Ambiente - SCEN - Av. L4, Trecho 2 - CENAFLOR - Asa Norte - 70818-900 - Brasilia, DF - ricardovilar@yahoo.com.br
}

Cerne, Lavras, v. 16, n. 3, p. 391-398, jul./set. 2010 
funcionam sob variadas condições ambientais, entretanto a cobertura florestal e o relevo de algumas áreas podem afetar a recepção dos sinais. O uso de equipamentos que permitam obter posicionamento com precisão de centímetros, é primordial para o planejamento florestal (FRANKLIN, 2001). Nesses requisitos, torna-se necessário a utilização de equipamentos GPS com correção diferencial, seja para determinação de áreas como para localização ou marcação de espécies florestais.

Utilizando a tecnologia GPS nos modos estático diferencial (posicionamento relativo) e estático absoluto em uma área de floresta natural de Araucária (Floresta Ombrófila Mista), objetiva-se, no presente trabalho:

a) determinar o posicionamento de todas as Araucárias que ocorrem na área de estudos e a precisão de seu mapeamento;

b) analisar a influência da vegetação e da declividade na recepção dos sinais GPS.

\section{MATERIAL E MÉTODOS}

\section{1 Área de estudo}

A área de estudo (Campus Universitário de Irati), com aproximadamente 70 hectares, caracteriza-se como um fragmento da Floresta Ombrófila Mista, com características naturais de floresta secundária em estágio avançado de regeneração em alguns pontos e áreas severamente antropizadas em outros, localizada na área da Universidade Estadual do Centro-Oeste (Unicentro). O relevo possui variações de altitude de $820 \mathrm{~m}$ até $890 \mathrm{~m}$, apresentando áreas planas e locais com declividade acentuada. O clima é temperado $\mathrm{Cfb}$, com geadas intensas no período de inverno.

\subsection{Materiais e softwares utilizados}

Foram utilizados uma imagem de satélite, um mapa planialtimétrico digital, dois receptores GPS e diversos softwares de processamento de dados GPS e de sistema de informações geográficas.

A imagem de satélite Quickbird 2 foi obtida em 7 de abril de 2004; projetada em sistema de coordenadas UTM e georreferenciada ao elipsóide de referência WGS 84, formato GeoTiff e com resolução espacial de $0,61 \mathrm{~m}$. A imagem havia sido tratada digitalmente, pela empresa fornecedora, e fusionada usando a banda pancromática e as bandas multiespectrais do azul, verde e vermelho. A licença da imagem fusionada, colorido normal foi adquirida pela Prefeitura Municipal de Irati, abrangendo uma área de cerca de $200 \mathrm{~km}^{2}$. A parte da imagem utilizada (3.768 linhas por 3.194 colunas), correspondente ao Campus Universitário de Irati, foi recortada da imagem original.

O mapa planialtimétrico digital utilizado no trabalho, elaborado pela empresa de engenharia de transportes e geomática Engefoto (sediada em Curitiba - PR), a partir de fotografias métricas obtidas no ano de 1996 (programa PARANACIDADE, do Governo do estado do Paraná), apresentava curvas de nível com equidistância vertical de um metro.

O receptor GPS de navegação, utilizado no modo estático absoluto, foi o marca/modelo Garmim Venture HC, o qual foi projetado para corrida de aventura, com antena de alta sensibilidade e possibilidade de recepção de sinal sob cobertura de árvores com grande rapidez. A antena é interna e a recepção é somente do sinal C/A. O receptor DGPS, utilizado no modo estático diferencial, foi o de marca/modelo Leica SR 20, de simples frequência (L1), com antena externa AT 501 Pole; além disso, possui um sistema ClearTrak Multipath Mitigation, que reduz o problema do multicaminhamento de sinais (LEICA GEOSYSTEM, 2008).

Os softwares utilizados para o processamento de dados GPS foram: Leica Geo Office 4.0, Posição 2000, Autocad MAP 2000, MapSource 6.11.6, MapDekode 5.2, GPS TrackMaker 13.5 Limited Edition. O software utilizado para o armazenamento de dados e produção de mapas foi o SPRING 5.02.

O material de apoio constituiu-se de trena de 5 e 20 metros, bússola, Barra de Bitterlich, bipé para antena do DGPS, pranchetas e blocos para anotações.

\subsection{Coleta de dados GPS}

O receptor GPS de navegação (Garmin Etrex Venture HC) foi utilizado em conjunto com o receptor DGPS (Leica SR20) para a coleta de pontos e a consequente localização das Araucárias dentro da área do Campus de Irati. Todas as coletas foram feitas no sistema de coordenadas WGS 84 - World Geodetic System.

A tomada do ponto com GPS foi efetuada com o receptor colocado em distância aproximada de $5 \mathrm{~cm}$ da árvore e cuja precisão das coordenadas captadas era indicada no visor do aparelho no momento da coleta de dados e em seguida anotada. O receptor DGPS, montado sobre bastão específico e colocado próximo da árvore, era constituído de receptor, antena e cabo de conexão de antena. 
O sistema de posicionamento relativo utilizado no presente trabalho consistiu de bases fixas e um equipamento móvel. As bases fixas com dupla frequência (L1+L2), sob responsabilidade da empresa MANFRA, localizam-se em pontos estratégicos em vários estados. As mais próximas da área de estudo e realmente utilizadas estão posicionadas nas cidades de Guarapuava, Curitiba e Maringá, com linha de base de $80 \mathrm{~km}, 130 \mathrm{~km}$ e $240 \mathrm{~km}$, respectivamente (MANFRA, 2008).

O procedimento para a obtenção do posicionamento geográfico das Araucárias foi padronizado da seguinte forma: a) identificação da árvore através de plaqueta de identificação; b) ocupação do ponto com DGPS; c) ocupação do ponto com GPS; d) medição do DAP e do diâmetro da copa de Araucária. Em caso de impossibilidade de obtenção de sinal favorável, ou seja, GDOP ou número mínimo de satélites insuficiente para os receptores GPS e DGPS, por um período superior a 15 minutos, em cada ponto, a ocupação era suspensa temporariamente. Nesse caso, ocorriam mais duas tentativas, em dias subsequentes, sempre com período de espera de 15 minutos. Em caso de impossibilidade de posicionamento que possibilitasse cálculo diferencial (posicionamento relativo), a posição era considerada baseada somente no posicionamento absoluto.

Os parâmetros utilizados para a coleta de dados (número mínimo de 4 satélites, Filtro GDOP < 6 e ângulo de corte de $15^{\circ}$ ) foram selecionados com base nas indicações do fabricante do aparelho, em Farret et al. (2006) e na Norma Técnica para Georreferênciamento de Imóveis Rurais, do Instituto Nacional de Colonização e Reforma Agrária (INSTITUTO NACIONAL DE COLONIZAÇÃO E REFORMA AGRÁRIA - INCRA, 2003). A inicialização do receptor era efetuada estacionando-se o aparelho em um ponto, por no mínimo 9 minutos, antes de iniciar a coleta de dados no modo Max Precision. Na impossibilidade da obtenção do sinal sob cobertura florestal, utilizou-se também o modo Hypertracking como segunda opção.

$\mathrm{Na}$ impossibilidade de obtenção do sinal devido ao relevo ou densidade da cobertura florestal, o ângulo de corte era reduzido gradativamente, até $5^{\circ}$, uma vez que o presente trabalho não objetivou precisão padronizada. A linha de base utilizada era superior a $100 \mathrm{~km}$, utilizando-se a solução "Float".

Os dados gravados na memória do receptor DGPS, durante as ocupações dos pontos, eram exportados no formado RINEX. O tratamento dos dados baseou-se na solução Code (código) para as medições, com cálculo do resíduo para as variáveis $\mathrm{dx}$, dy e dz.

O processamento das coordenadas UTM coletadas no terreno foi executado no software Leica Geo Office versão 4.0. Na sequência, houve a importação e conversão dos pontos utilizando o software Posição 2004, em ambiente Autocad.

\subsection{Elaboração dos mapas de vegetação, de área basal e de} declividade

O mapa de vegetação do Campus Universitário de Irati foi elaborado com vetorização sobre tela, no software SPRING 5.02, utilizando a imagem Quickbird. Foram consideradas cinco classes: vegetação rasteira (gramíneas ou vegetação em estágio inicial de regeneração), vegetação arbustiva (arbustos até 4 metros de altura ou vegetação em estágio intermediário de regeneração), vegetação arbórea (árvores com altura superior a 4 metros ou vegetação em estágio avançado de recuperação), pavimento e edificações.

O mapa de área basal do Campus Universitário de Irati foi elaborado com base no mapa de vegetação e utilizando princípios de relascopia. Utilizou-se uma Barra de Bitterlich de $25 \mathrm{~cm}$ de comprimento e abertura da mira de $1 \mathrm{~cm}$, e a fórmula aplicada foi $\mathrm{G}=\mathrm{KN}$ ( $\mathrm{G}=$ área basal; $\mathrm{K}=$ fator de área basal; $\mathrm{N}=$ número de árvores contadas na amostra), com K= 1 (FIGUEIREDO FILHO \& MACHADO, 2006). Foram determinados 100 pontos amostrais, distribuídos no Campus sistematicamente, com equidistância mínima entre pontos de 50 metros. Os pontos, colocados sobre a grid de coordenadas UTM, foram inseridos no receptor GPS Garmin Etrex Venture HC, como mapa de fundo. Os valores de área basal obtidos subsidiaram a elaboração do mapa de área basal do campus, produzido através do procedimento de Krigagem do software SPRING 5.02.

O mapa de declividade foi elaborado com o mapa planialtimétrico digital utilizando-se o software SPRING 5.02. A grade utilizada para geração do mapa de declividades considerou resolução de 1 metro $(X=1$ e $Y=1)$.

\section{RESULTADOS E DISCUSSÃO}

A Figura 1 reporta o mapa de vegetação da área de estudo. Dos 100 pontos amostrais utilizados para a elaboração do mapa de área basal, 10 pontos estavam na área de vegetação rasteira e 85 pontos na área de vegetação arbustiva e arbórea.

Cerne, Lavras, v. 16, n. 3, p. 391-398, jul./set. 2010 


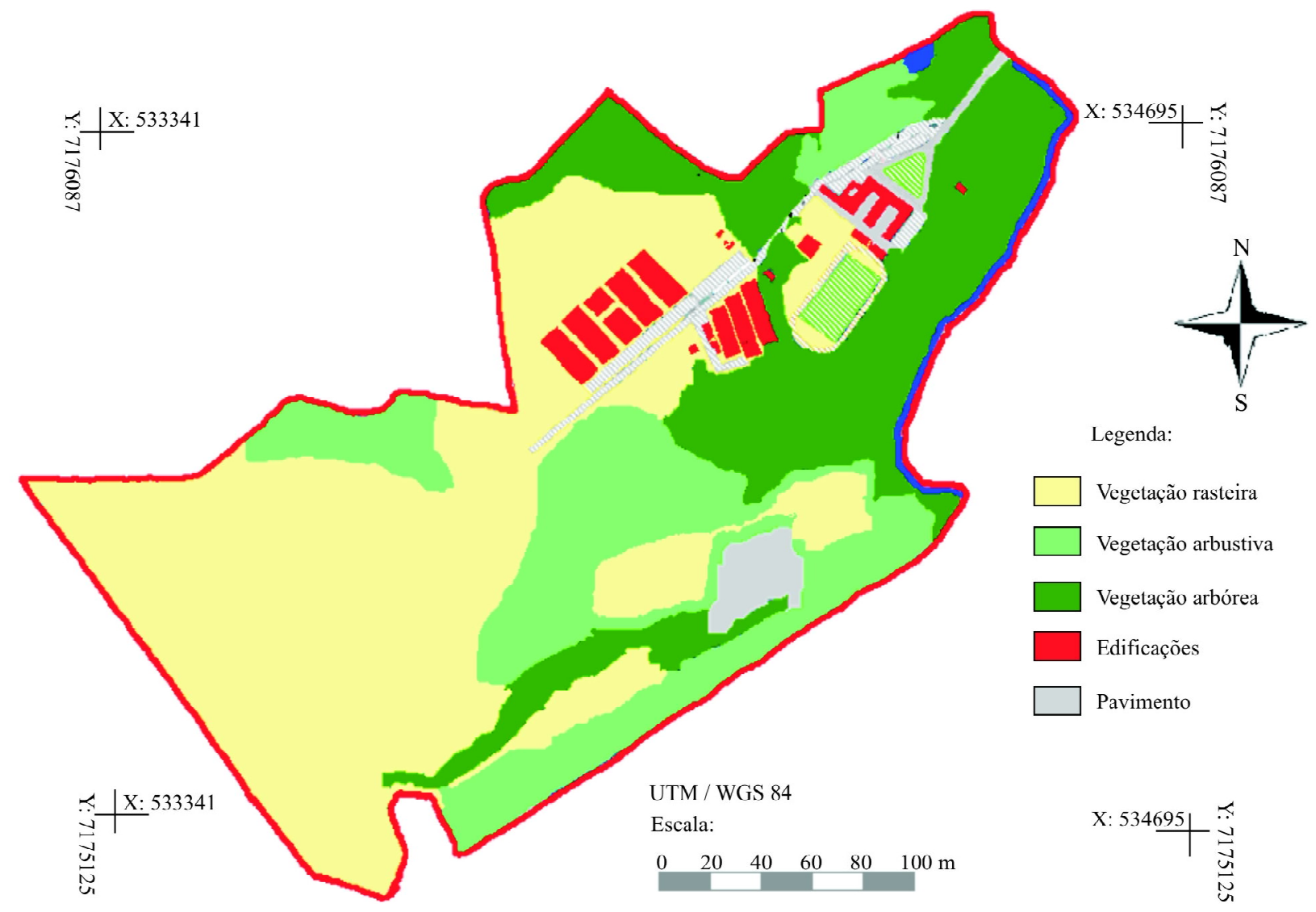

Figura 1 - Mapa de vegetação do Campus Universitário de Irati.

Figure 1 - Vegetation map of the Campus of Irati.

\subsection{O posicionamento das Araucárias com DGPS}

Foram ocupadas 264 Araucárias pontos com o receptor SR20. Cada ponto correspondia a uma Araucária com DAP superior a $10 \mathrm{~cm}$. A recepção de sinal DGPS só foi possível em 141 Araucárias (53,4\% do total), com processamento executado utilizando dados da base fixa de Curitiba (132 pontos) e Maringá (9 pontos). Nas restantes 123 Araucárias (46,6\%), nas três tentativas ou revisitas, não foi possível a obtenção de parâmetros mínimos que possibilitassem o cálculo diferencial.

$\mathrm{O}$ posicionamento relativo dependia de basicamente três fatores: obtenção do sinal, GDOP $<6$ e número de satélites igual ou superior a 4 . Dois fatores podem ser adicionados: cobertura vegetal e a declividade do terreno (a serem discutidos posteriormente), responsáveis pela interrupção do sinal em determinados momentos. O posicionamento absoluto era dependente somente do número de satélites, igual ou superior a 4 .
A recepção do sinal dos satélites pela antena do DGPS sofreu interrupções em diversas ocasiões, devido à vegetação e o fuste (tronco) da árvore. Em uma situação ideal, a antena deveria ser posicionada acima da copa da Araucária, reduzindo o efeito do multicaminhamento devido aos galhos, acículas, mas de procedimento prático inviável visto a altura das Araucárias atingirem valores superiores a $25 \mathrm{~m}$. A obstrução do sinal reduz o número de satélites disponíveis, reduzindo assim a capacidade de utilização de valores de GDOP baixos. Lohani \& Kumar (2006) destacaram a interrupção dos sinais GPS pela vegetação e pelo relevo.

Entre as dificuldades encontradas no trabalho de campo, além da perda de sinal e GDOP insuficiente, ocorreram alguns problemas relacionados a fatores naturais. A estrutura do bipé teve que ser retirada do equipamento em alguns pontos, devido a problemas com cipós e vegetação rasteira. $\mathrm{O}$ transporte do equipamento 
ligado (bastão + receptor) ocupa as duas mãos do operador, dificultando o deslocamento em locais de mata fechada. A opção mais segura de transporte do equipamento por longas distâncias (mais de 200 metros) na floresta é o desligamento do aparelho, porém, nesse caso é necessário fazer novo ponto de inicialização com permanência média de 10 minutos no ponto. Apesar do potencial do modo estático diferencial GPS para o posicionamento e consequente individualização de árvores, necessários para uma série de experimentos científicos, os aspectos acima comentados evidenciam sérias barreiras para o seu uso no interior da floresta.

\subsection{O posicionamento absoluto das Araucárias}

O posicionamento absoluto obtido com receptor de mão Etrex Venture HC foi possível em todas as 264 Araucárias, independente da declividade da área ou cobertura florestal, mas ocorrendo redução de precisão no posicionamento (valores no item 3.3).

\subsection{Precisões associadas ao posicionamento absoluto e relativo}

A condução de experimentos científicos depende muitas vezes da capacidade de individualização das árvores, evitando erros nas repetições dos experimentos. A individualização de árvores depende basicamente da precisão obtida pelo posicionamento. Uma precisão de 10 metros indica que determinada árvore está localizada em um círculo de até 10 metros de raio do ponto ocupado. A existência de outra árvore da mesma espécie nesse limite possibilita a ocorrência de erro em remedições de experimentos.

Verificou-se, no presente estudo, a possibilidade de confusão de Araucárias devido à precisão do posicionamento. No posicionamento relativo, a precisão média obtida foi de $25 \mathrm{~cm}$, com valores variando entre $6 \mathrm{e}$ $84 \mathrm{~cm}$. No posicionamento absoluto, a precisão média obtida foi de 9 metros, com valores variando de 5 a 14 metros (valor informado no receptor no momento da ocupação do ponto). Utilizando-se o software SPRING foi gerado o mapa de distâncias (buffer) ao redor de pontos representando Araucárias, utilizando-se os valores médios de posicionamento absoluto e relativo.

A possibilidade de utilização do posicionamento relativo em todos os 264 pontos ocupados, considerando uma precisão média de $25 \mathrm{~cm}$, não causaria nenhuma confusão de árvores, ou seja, elas estavam dentro do raio de precisão média obtida. Considerando-se o valor mínimo de precisão $(84 \mathrm{~cm})$ no posicionamento relativo, ocorreriam somente duas situações de possibilidade de confusão de árvores.

A utilização do posicionamento absoluto em todos os 264 pontos ocupados, com precisão média de 9 metros causaria confusão de árvores envolvendo 74 Araucárias (28\%). Considerando-se o valor mínimo de precisão (14 metros), o valor subiria para 137 Araucárias (51,9\%).

A média de raio das copas encontradas no Campus é de 4 metros (área aproximada da copa de $48 \mathrm{~m}^{2}$ ). Assim, a precisão mínima exigida por um método qualquer de posicionamento, considerando o presente estudo, para individualização de árvores é de 4 metros. Assim, o valor médio do posicionamento absoluto, com precisão média de 9 metros, praticamente inviabiliza a correta individualização das copas de Araucária.

\subsection{Posicionamento das Araucárias relacionado á declividade da área}

A declividade da área de estudo é bastante diversificada, com predominância de áreas de baixa declividade e ocorrência de locais onde os valores do declive atingem $40 \%$ ou mais. Em relação ao posicionamento das Araucárias, houve uma grande influência do relevo, representado pela declividade da área. Devido à situação da área de estudo, altamente antropizada em alguns locais, mas com características de floresta natural em outros pontos, e a disposição não homogênea das Araucárias no terreno, pode-se observar uma predominância de árvores em locais de alta declividade.

Considerando-se o total de 264 Araucárias existentes na área de estudo, a maioria ocorre na região de maior declividade. Em porcentuais, 59,8\% das árvores consideradas no estudo estão em locais onde os valores de declividade estão acima de 30\%; na área intermediária, com declividades de 20 a $30 \%$, estão localizadas $22,4 \%$ das árvores; e em regiões mais planas (abaixo de 20\%), localizamse $17,8 \%$ das árvores.

O posicionamento relativo é dependente de vários fatores como número mínimo e geometria de satélites, ângulo de corte e tempo de permanência no ponto. Além desses fatores é preciso realizar um processo de inicialização do aparelho, permanecendo estacionado em um ponto sem cobertura vegetal por 10 minutos. Nas áreas de menor declividade, $100 \%$ das Araucárias possibilitaram o cálculo diferencial, ou seja, possibilitaram posicionamento relativo. $\mathrm{Na}$ área de declividade intermediária, $81 \%$ das árvores (48 de 59 árvores)

Cerne, Lavras, v. 16, n. 3, p. 391-398, jul./set. 2010 
possibilitaram o posicionamento relativo. $\mathrm{Na}$ área de maior declividade, $29 \%$ das árvores possibilitaram o posicionamento relativo. A questão do relevo como fator interveniente na recepção dos sinais de satélite também foi destacado por Ângulo Filho et al. (2002).

\subsection{Posicionamento relacionado à área basal $\left(\mathrm{m}^{2} / \mathrm{ha}\right)$}

A consideração da densidade da vegetação foi pela área basal $(\mathrm{G})$. Existiam locais onde as Araucárias encontravamse isoladas ou em áreas onde os valores de área basal eram < $1 \mathrm{~m}^{2} / \mathrm{ha}$. Em outros locais, a área basal era superior a $25 \mathrm{~m}^{2} / \mathrm{ha}$. Entretanto, mesmo em áreas de elevados valores de $\mathrm{G}$, ocorria recepção de sinal e possibilidade de posicionamento relativo.

A grande maioria (76\%) das Araucárias situa-se em locais com área basal acima de $16 \mathrm{~m}^{2} / \mathrm{ha}$. $\mathrm{O}$ restante apresenta-se em áreas de baixa densidade ou locais de vegetação em estágio primário ou secundário de regeneração. Os valores de área basal na área de estudo apresentaram um máximo de $35 \mathrm{~m}^{2} / \mathrm{ha}$, enquanto que em outras áreas (por exemplo, a Floresta Nacional de Irati, distante $20 \mathrm{~km}$ da área de estudo) frequentemente os valores são superiores a $36 \mathrm{~m}^{2} / \mathrm{ha}$.

O posicionamento relativo foi possível em 141 Araucárias, sendo que 56 árvores encontram-se em locais de baixos valores de área basal. Na área de valores elevados de área basal, foi utilizado o posicionamento relativo para 85 árvores.

\subsection{Posicionamento relativo referente a declividade e área basal}

A utilização de ferramentas como cruzamento de planos de informação, no software SPRING, permitiu obter informações derivadas de dois planos de informação. A Figura 2 apresenta a ocorrência de Araucárias no local de estudo e em destaque a área de maior declividade (>30\%) e maior área basal $\left(>16 \mathrm{~m}^{2} / \mathrm{ha}\right)$.

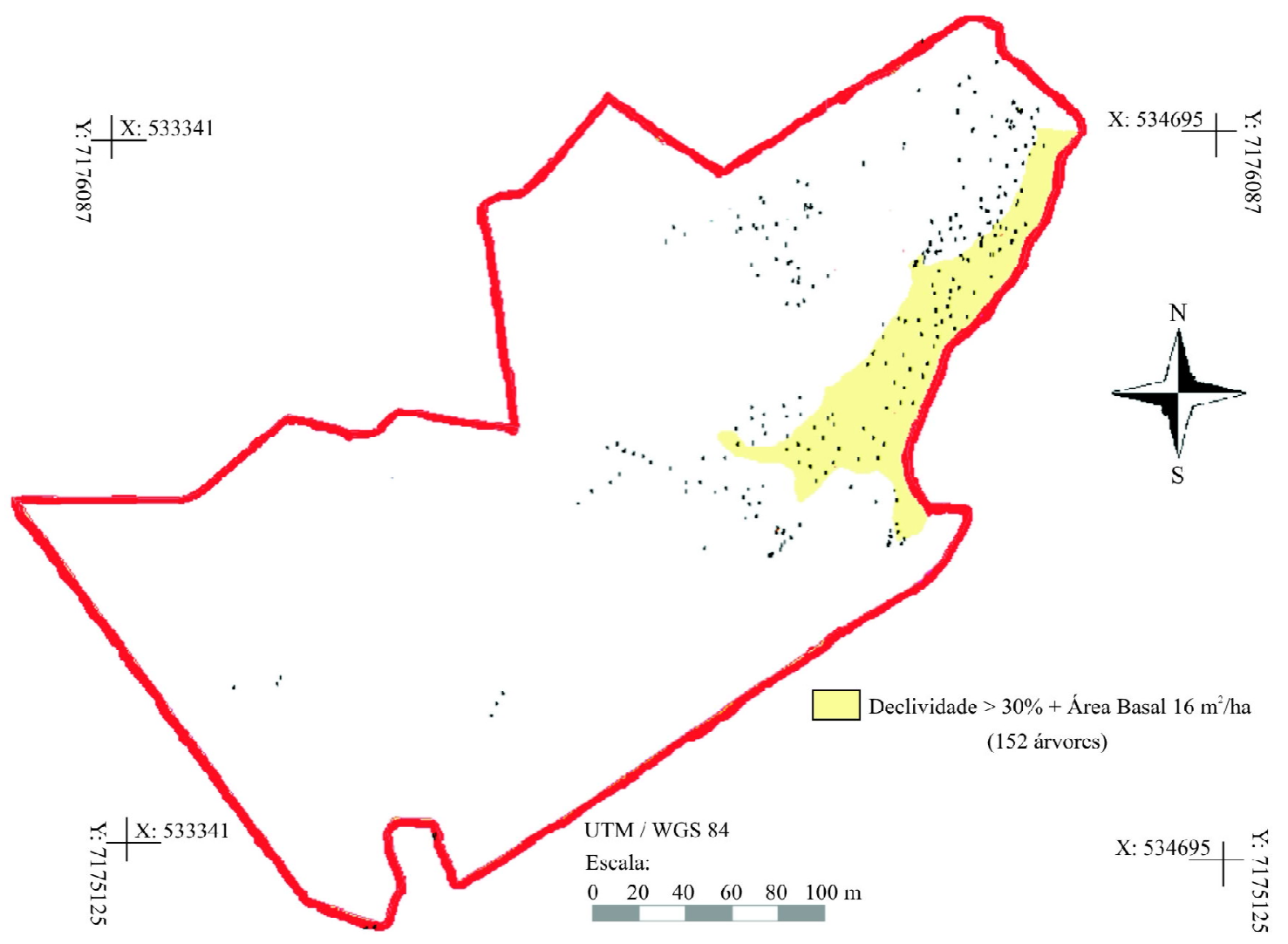

Figura 2 - Araucárias localizadas em áreas de maior área basal e em alta declividade.

Figure 2 - Araucárias located in places with bigger values of basal area and high slope.

Cerne, Lavras, v. 16, n. 3, p. 391-398, jul./set. 2010 
Os locais onde ocorrem altas declividades associado aos valores elevados de área basal, apresentou a ocorrência de 152 Araucárias. Desse total, o posicionamento relativo foi possível em 38 árvores. A associação dos dois fatores afetou de forma decisiva o posicionamento relativo, pois a impossibilidade de obtenção de baixos valores de GDOP impossibilita o cálculo diferencial.

A declividade apresentou interferência na possibilidade de obtenção de posicionamento relativo. A situação apresenta-se de forma mais proeminente quando ocorre associação de declividades elevadas (> 30\%) e valores de área basal elevada ( $\left.>16 \mathrm{~m}^{2} / \mathrm{ha}\right)$. O presente trabalho foi executado com permanência de 150 segundos no ponto, baseado em Farret et al. (2006). A permanência no ponto por um período maior de tempo pode apresentar resultados diferentes.

\section{CONCLUSÕES}

O mapa, elaborado com base na tecnologia GPS, indicou a localização geográfica de 264 Araucárias presentes na área de estudo, com uma precisão média variando de: a) 6 a $84 \mathrm{~cm}$ em 141 Araucárias posicionadas, utilizando-se posicionamento relativo; b) 5 a $14 \mathrm{~m}$, em todas as Araucárias existentes na área, utilizando-se posicionamento absoluto.

O uso da tecnologia GPS no modo absoluto permitiu o posicionamento de todas as Araucárias na área estudada, porém não resultaram valores de precisão compatíveis com a necessidade de individualização das Araucárias.

A recepção de sinal pelo receptor DGPS com configuração mínima para obtenção de posicionamento relativo é significativamente comprometida no interior da floresta, devido a interferência da declividade e vegetação, limitando seu uso prático.

A utilização do posicionamento relativo possibilitou que 141 Araucárias $(53,4 \%$ do total) tivessem seu posicionamento determinado com nível de precisão capaz de evitar a confusão com outras árvores próximas.

\section{AGRADECIMENTOS}

À Fundação Araucária pelo apoio financeiro à pesquisa "Fotografias aéreas versus imagens satelitárias de altíssima resolução no delineamento de copas de Araucária" que subsidiou uma dissertação de mestrado da qual foi extraído o presente artigo.

\section{REFERÊNCIAS BIBLIOGRÁFICAS}

ÂNGULO FILHO, R.; VETORAZZI, C. A.; SARRIES, G. Exatidão de posicionamento de um receptor GPS, operando sob diferentes coberturas florestais. Revista Brasileira de Engenharia Agrícola e Ambiental, Campina Grande, v. 6, n. 2, p. 325-331, 2002.

BERNARDI, D.; PONTES, C. R. Utilização de pocket GPS no microplanejamento florestal. In: SEMINÁRIO EM ATUALIZAÇÃO EM SENSORIAMENTO REMOTO E SISTEMAS DE INFORMAÇÕES GEOGRÁFICAS APLICADOS A ENGENHARIA FLORESTAL, 7., 2006, Curitiba. Anais... Curitiba: FUPEF/DEF, 2006. p. 614-621.

EL-SHEIMY, N.; WRIGHT, D. B. Real time forest fire fighting thought integration of infrared video, GPS and INS systems: TS 19 best practice in positing. Paris: [s.n.], 2003. 17 p.

FARRET, J. C.; SANTOS, M. C.; MORAES, C. C.; PEREIRA, R. A. A precisão possível com GPS L1/CA em georreferenciamento: o desafio do multicaminho no projeto de um receptor com código suavizado. Boletim de Ciências Geodésicas, Curitiba, v. 12, n. 2, p. 353-372, jul./dez. 2006.

FIGUEIREDO, E. O.; MESQUITA, R. C.; BRAZ, E. M.; FIGUEIREDO, S. M. de M.; NEVES, M. V. d' O. Avaliação de procedimentos para localização de árvores em inventários florestais censitários, visando o emprego do manejo de precisão. In: SIMPÓSIO LATINO AMERICANO SOBRE MANEJO FLORESTAL: PRODUÇÃO DE BENS MATERIAIS E IMATERIAIS, 4., 2008, Santa Maria. Anais...Santa Maria: UFSM, 2008. CD-ROM.

FIGUEIREDO FILHO, A.; MACHADO, S. A. Dendrometria. 2. ed. Guarapuava: Unicentro, 2006.

FRANKLIN, S. E. Remote sensing for sustainable forest management. New York: Lewis, 2001. 407 p.

INSTITUTO NACIONAL DE COLONIZAÇÃO E REFORMA AGRÁRIA. Norma técnica para georreferênciamento de imóveis rurais. 2003. Disponível em: Lhttp $120 \mathrm{~T} \%$ C3\%A9cnica.pdf

LEICA GEOSYSTEMS. Leica GS20 professional data mapper. 2008. Disponível emi $<$ http:// www.leicagesystems.com icorporate/en/products/mobile_mapping/lgs_4502.htm em: 25 nov. 2008.

Cerne, Lavras, v. 16, n. 3, p. 391-398, jul./set. 2010 
LOHANI, B.; KUMAR, R. A model for GPS-GDOP prediciton in urban environment using lidar data. Kanpur: Department of Civil Engineering, 2005.

MANFRA. Bases fixas. 2008. Disponível em: <http:// Www.manfra.com.br/bases.php. Acesso em: 21 set. 2008.

MONICO, J. F. G. Posicionamento pelo NAVSTAR-GPS: descrição, fundamentos e aplicações. São Paulo: UNESP, 2000. 288 p.

NAESSET, E. Effects of differential single- and dual-frequency GPS and GLONASS observations on point accuracy under forest canopies. Photogrammetric Engineering \& Remote Sensing, New York, v. 67, n. 9, p. 1021-1026, Sept. 2001.
OHMA, M.; MIETTINEN, M.; KOSTI, K.; JUTILA, J.; VISALA, A.; FORSMAN, P. Tree measurement and simultaneous localization and mapping system for forest harvesters. In: INTERNATIONAL CONFERENCE ON FIELD AND SERVICE ROBOTICS, 6., 2007, Paris. Anais... Paris, 2007. Disponível em: ǩktttp://autsys.tkk.fi/en/Publications/53699-1 Acesso em: 4 abr. 2009.

RODRIGUES-PEREZ, J. R.; ALVAREZ, M. F.; SANZ, E.; GAVELA, A. Comparison of GPS receiver accuracy and precision in Forest environmental. In: PRACTICAL RECOMMENDATIONS REGARDING METHODS AND RECEIVER SELECTION, SHAPING THE CHANGES, 23., 2006, Munich. Proceedings... Munich, 2006. CD-ROM.

Cerne, Lavras, v. 16, n. 3, p. 391-398, jul./set. 2010 